\title{
References:
}

1. Richard E. Mayer. Multimedia Learning. New York, NY: Cambridge University Press. 2001. - 318 pp.

2. Jang F.M. Graat. How to Give a Great Presentation! URL: http://www.pc.maricopa.edu/data/GlobalFiles/file/learning (date access: 2.07.2021)

DOI https://doi.org/10.30525/978-9934-26-110-7-63

\section{СТРУКТУРНЫЕ ТРАНСФОРМАЦИИ ПРЕДЛОЖЕНИЯ ПРИ ПЕРЕВОДЕ}

\author{
Кириллова М. Д. \\ кандидат филологических наук, \\ доиент кафедры теории и практики перевода \\ Одесский национальный университет имени И. И. Мечникова \\ 2. Одесса, Украина
}

Перевод как «двуязычный коммуникативный акт требует учета всех изменяющихся при переводе факторов, в том числе получателя и социальной ситуации» [5, с. 247]. Следовательно, не только несовпадение формальных элементов контактирующих языков, но и особенности коммуникативной ситуации существенно влияют на процесс и результат перевода. Именно взаимодействие этих двух аспектов порождает все трансформации и несоответствия в области формы и в области содержания, имеющие место при переводе с одного языка на другой. На системные различия неизбежно накладывается влияние "идиолекта переводчика, выступающего в роли получателя сообщения и его перекодировщика" [4, с. 93]. При переводе происходит обязательная адаптация текста к новому получателю.

Научный анализ структурных трансформаций предложения при переводе свидетельствует, что они охватывают прежде всего сложное предложение и распределяются по трем основным направлениям:

1. изменение состава сложного предложения;

2. изменение типа связи между его составляющими;

3. изменение порядка их следования.

Важность сохранения состава сложного предложения в переводе самоочевидна, ибо изменение количества, типа и порядка следования составляющих влечет за собой существенные содержательные и 
стилистические сдвиги. Однако, полные соответствия структур составляют лишь часть переводных предложений каждого типа. Основная же их масса - результат структурных преобразований, проведенных по воле переводчика.

Под влиянием переводческого восприятия оригинального текста изменяется и порядок следования составляющих сложного предложения.

Breasley himself came in from the garden as David stood at the foot of the stairs uncertain of where breakfast took place (ET).

Он стоял в нерешительности у подножия лестниць, не зная, куда идти завтракать, а в это время в холл со стороны сада вышел Бресли.

He might have excited sympathy if he had grown worn and thin (ET).

Если бы он хоть немного похудел и осунулся, он возбуждал бы жалость.

Инверсия клаузов сложного предложения ведет к перераспределению смысловых связей внутри такого предложения, экспликации одних и затушевывании других. Как каждая трансформация, инверсия неизбежно сопровождается большими или меньшими смысловыми сдвигами, что проистекает из самой природы неравноправных отношений главного и придаточного предложений.

Существенное значение имеет и замена типа связи в переводном предложении, которая ведет к перераспределению и частичному изменению типов информации, представленных в оригинальном тексте. Изменений концептуальной информации они не несут, что же касается содержательно-фактуальной информации (СФИ), то изменяется дозировка и организация ее подачи [5]. Наибольшие смещения претерпевает содержательно-подтекстовая информация (СПИ) эксплицируются имплицитные связи, создаются новые, изымаются имеющиеся.

Помимо информативных изменений, трансформация связей между отдельными предложениями и их частями полностью изменяет членение текста на СФЕ, чему способствуют и лексические (номинативнопрономинальные и номинативно-адвербиальные) замены. Результатом указанного перераспределения связей является, в большинстве своем, усиление текстовой когезии, которое можно рассматривать как синтаксическую компенсацию ее ослабления на лексическом уровне, связанного с уменьшением роли сквозных лексических повторов, синонимизацией высокочастотных слов и прочими последствиями несовпадений семантических структур исходных и переводных лексем. 
Обобщая результаты исследования, отметим:

1. Преобразования переводимого художественного текста неизбежны в связи не только с разносистемностью исходного и переводного языков (объективный фактор), но и интерферирующим включением переводчика (субъективный фактор).

2. Системно обусловленные трансформации затрагивают прежде всего структуру предложения. Усечение строевых слов, замена аналитических форм флективными влечет за собой повсеместное сокращение длины предложения. Изменения структуры, таким образом, можно рассматривать как причину, следствием которой выступает изменение длины.

3. Субъективно обусловленные трансформации связаны с индивидуальной переводческой квалификацией ценности информации, передаваемой текстом исходного языка, и направлены на ее экспликацию. Собственным решением переводчика часть информации усекается, часть, наоборот, разворачивается и детализируется. В обоих случаях частично или полностью меняется структура, а с ней и длина предложения.

4. Полное совпадение длины и структуры предложения ИЯ и ПЯ имеет место лишь в 4\% всех предложений текста и осуществляется только в пределах простых структур объемом до 5 слов. В связи с этим наличие идентичных длин в оригинальном и переводном текстах не означает их зеркального соответствия друг другу, но отражает разные составы рубрик с одинаковыми показателями длин: группа определенного диапазона длин ПЯ наполняется за счет трансформированных структур ИЯ, принадлежавших в исходном тексте к иным диапазонам.

5. Изменения рассмотренных характеристик предложения ведут к перераспределению внутри- и межфразовых связей, что, в свою очередь, сказывается на изменении средств текстовой когезии. Потери в этой области, связанные с изменением тема-рематического членения и лексическими заменами, частично компенсируются экспликацией структурных отношений, предпринимаемой переводчиком.

6. Поскольку давление языковой системы в процессе перевода является постоянно действующим фактором, принципиальную возможность создания разных переводов одного исходного текста и их фактическое наличие следует объяснить исключительно действием фактора субъективного, переменного - личности переводчика во всем многообразии его личностных и социально-исторических характеристик. 


\title{
Литература:
}

1. Гарбовский Н.К. Теория перевода: Учебник. М.: Изд-во Московского университета, 2004. 544 с.

2. Золотова Г.А. О роли семантики в членении предложения // Вопросы истории языка и современного состояния. М.: Высшая школа, 1998. C. $142-162$.

3. Слюсарева Н.А. Гиперсинтаксический уровень языка в лингвистическом членении текста // Предложение и текст в семантическом аспекте. Калинин: КГУ, 1993. С. 93-111.

4. Тюленев С.В. Теория перевода: Учебное пособие. М.: Гардарики, 2004. $336 \mathrm{c}$.

5. Черняховская Л.А. Перевод и смысловая структура. М.: Международные отношения, 1976. 262 с.

6. Fowles J. The Ebony Tower. London: Granada publishing, 1974. 115 р. Фаулз Дж. Башня из черного дерева // ИЛ, 1979. № 3. С. 115-185. Перевод с англ. К.Чугунова.

DOI https://doi.org/10.30525/978-9934-26-110-7-64

\section{TRANSLATION OF JURIDICAL TERMS IN AMERICAN NOVELS}

\author{
Mosiyevych L. V. \\ Candidate of Philological Sciences, \\ Associate Professor at the Department of General Education \\ Institute of Education and Science in Engineering \\ Zaporizhzhia National University \\ Zaporizhzhia, Ukraine
}

The main application area of terminological vocabulary is official and scientific style. However, entering the various genres of fiction, terminological vocabulary acquires expressive stylistic functions. In our paper, we will use definition of a term provided by L'Homme: «the term is a word or a phrase that is used to express a concept, accepted in a relevant professional field and used in specific conditions» [4, p. 55]. In recent years, the Ukrainian linguists Bilozerska, Voznenko, \& Radetska [1], Karaban [3] etc. have been actively working out issues of terminology translation, standardization of national terminology and the compilation of terminology dictionaries. Despite the narrow specialization of most terms, their use in fiction does not interfere with the reader's perception [2, p. 198]. 